Research Article

\title{
Performance-Based Seismic Fragility and Risk Assessment of Five-Span Continuous Rigid Frame Bridges
}

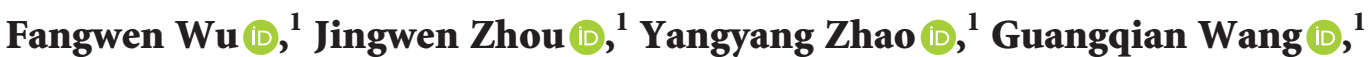 \\ Wenlong Tang $\mathbb{D}$, , Jianfei Luo $\mathbb{D}$, ${ }^{1}$ Usama Ibrahim $\mathbb{D}^{1},{ }^{2}$ and Yuanying Meng $\mathbb{D}^{3}$ \\ ${ }^{1}$ School of Highway, Chang'an University, Xi'an 710064, China \\ ${ }^{2}$ School of Civil Engineering, Chang'an University, Xi'an 710064, China \\ ${ }^{3}$ Guangzhou Communications Investment Group Co., Ltd., Guangzhou 510288, China
}

Correspondence should be addressed to Fangwen Wu; wufangwen2004@163.com

Received 19 October 2020; Revised 22 March 2021; Accepted 26 March 2021; Published 9 April 2021

Academic Editor: Filipe Santos

Copyright (C) 2021 Fangwen Wu et al. This is an open access article distributed under the Creative Commons Attribution License, which permits unrestricted use, distribution, and reproduction in any medium, provided the original work is properly cited.

Earthquakes can cause serious damage to traffic infrastructures, among which the impact on bridge structure is the most important. Therefore, in order to assess bridges serviceability, it is important to master their damage mechanism and to analyze its probability of occurrence under a given seismic action. Various uncertainties, like the location of epicentre of future earthquakes and their magnitudes, make this task quite challenging. We are also required to consider different earthquake scenarios and the damaged states of bridge components associated with those earthquakes. To suppress these difficulties, this study proposed a new method of performance-based seismic fragility and risk assessment for bridges. The proposed method included three steps: (1) performance-based seismic fragility estimation of a five-span continuous rigid frame bridge, (2) seismic hazard analysis for locations of the bridge, and (3) seismic risk analysis of the bridge. The proposed method that considered the performance of the bridge and the uncertainty in the location of the earthquake epicentre and magnitudes can provide valuable references for seismicresistant design of multispan continuous rigid frame bridges in the future.

\section{Introduction}

In recent years, the subject dealing with safety of bridge structures has seen utmost growth and has evolved drastically. The safety of the bridge structure has received widespread attention exposed to seismic hazards. Since the 20th century, nearly 70 earthquakes of magnitude 7 or above have occurred in western China. Taking into account the topographic features of deep valleys in western region, continuous rigid frame bridges have become the preferred bridge type due to their advantages of good terrain adaptability and convenient construction method [1-3]. However, on account of complex mechanical structure and the lack of evaluation methods, their working performance has not been well understood when subjected to seismic excitation $[4,5]$. If an earthquake occurs, it may endanger the stability of the bridge structure and threaten people's lives and property security. Severe earthquakes might even cause bridge to collapse. Highway bridges are an important part of lifeline system engineering. In the earthquake relief work, ensuring safe and smooth traffic is conducive to resuming production, rebuilding homes, and reducing secondary disasters. In order to investigate the seismic response mechanism of continuous rigid frame bridges, a large number of researches have been carried out, including numerical simulations and theoretical analyses.

Numerical simulation of continuous rigid frame bridges analyzes their performance in consideration with multiple factors such as traveling wave effect and long period seismic waves. According to the researches performed by Chen et al., traveling wave effect has great influence on the fragility of long-span continuous rigid frame bridge in mountainous areas. They found that low piers have more probability of encountering damage as compared to high piers [6]. Zhao et al. analyzed the influence of the double effects of actual site and collision on the fragility of high-pier and long-span 
continuous rigid frame bridge, which was related to the heights of piers of the bridge structure [7]. Jiang et al. studied the probabilistic seismic damage characteristics of deepwater continuous rigid frame bridge, which took the influence of pile-soil dynamic interaction and hydrodynamic effect into account for the submerged parts [8]. Akbari investigated the seismic fragility of continuous rigid frame bridge by modifying the design parameters of pier height [9]. Based on the time-varying law of the seismic sequence of main aftershocks, Liang et al. discussed time-varying seismic fragility of an offshore bridge with continuous rigid frame bridge in service period [10]. Pang et al. carried out a research on two continuous rigid frame bridges incorporated with steel fiber. The results of the analysis revealed that steel fiber reinforced concrete was capable of effectively improving the earthquake resistance of bridge structures [11]. In addition, influence factors like material deterioration, seismic excitation mode, long-period seismic waves, and the conditions of engineering were also taken into consideration [12-15].

The obtained results from current studies have greatly promoted the application of long-span continuous rigid frame bridge in the field of civil engineering. When we deal with future earthquakes, we encounter different types of uncertainties like the location of the epicentre, the magnitude, and when and under which conditions they would occur. These problems have limited the studies of researchers and have restricted the development of long-span continuous rigid frame bridge. Although many theories and methods were proposed, they have not yet achieved an accurate method for the seismic response mechanism under different earthquake intensities. Designing a continuous rigid frame bridge with these theories and model causes us to encounter various complications like extravagant use of materials, excessive economic costs, and so forth.

Following the aforementioned extensive review, the research on seismic fragility and seismic risk of continuous rigid frame bridges with high piers is still in the exploratory stage. Hence, the purpose of this paper is to provide an adaptive methodology to evaluate seismic fragility and seismic risk of continuous rigid frame bridges with high piers. Firstly, taking into account the inconsistency of the longitudinal and transverse main periods of the bridge structure and the uncertainty of ground motions, 10 adjusted actual seismic waves were input for incremental dynamic analysis. Secondly, according to the damage index of each key section and the seismic demand value under different intensity earthquakes, the seismic fragility curves of each key section are obtained. Then, based on the seismic hazard curves of spectral acceleration $\mathrm{S} a$ and results of seismic fragility, the risk function of the bridge structure is derived. Furthermore, the annual risk probability (longitudinal and transverse) of the bridge structure is obtained as well as the risk probability of the design reference period. Finally, the seismic resistance of the structure is evaluated according to the risk probability.

\section{Methods and Theories}

2.1. Method of Seismic Fragility Analysis and Evaluation Index. Seismic fragility refers to the probability that a structure will be damaged to different degrees under different levels of earthquake intensity or the probability that the structure will exceed a certain limit state (performance level). The result of seismic fragility analysis is usually expressed by fragility curves.

2.1.1. Damage Quantification of the Bridge Pier Section. In the process of analyzing the seismic fragility of the bridge structure, it is essential to determine the performance target and quantify the damage state for the structure. According to the assessment methods of section damage, researchers put forward Park index, capacity demand ratio index, crack index, displacement ductility ratio index, and curvature ductility index. These five methods can be used to quantitatively analyze structural damage.

As in case of high-rise structures, curvature-ductility method is most suitable, so we are going to adopt this method for our study $[16,17]$. The damage that key sections of the bridge undergo is divided into four different categories: slightly damaged, moderately damaged, severely damaged, and completely damaged. The corresponding limit curvature is defined as $\varphi_{1}, \varphi_{2}, \varphi_{3}$, and $\varphi_{4}$, respectively. The damage range of the section is divided by the relation between the section bending moment curvature and the strain limit of the material [18], shown in Figure 1. The characteristics of curvature ductility index are shown in Table 1.

2.1.2. Seismic Fragility Probability Function. According to the theory of structural reliability, the functional function of components can be expressed in the following equation:

$$
Z=R-S \text {. }
$$

The failure probability of the component can be expressed by the following equation:

$$
P_{f}=P(Z<0)=P(R-S<0) .
$$

Assuming that the seismic capacity $R$ and capacity demand $S$ of the components conform to lognormal distribution, $(\ln R-\ln S)$ obeys the normal distribution. Thus, the fragility function of the members can be expressed in the following equation:

$$
\begin{aligned}
F_{s}(x) & =P[(\ln R-\ln S)<0] \\
& =P\left[\frac{(\ln R-\ln S)-\left(\ln R-\mu_{\ln S}\right)}{\sigma}<\frac{0-\left(\ln R-\mu_{\ln S}\right)}{\sigma}\right] \\
& =\Phi\left(\frac{\mu_{\ln S}-\ln R}{\sigma}\right),
\end{aligned}
$$

where $\Phi(\cdot)$ represents standard normal distribution function; $\ln R$ represents the logarithm of structural resistance, 


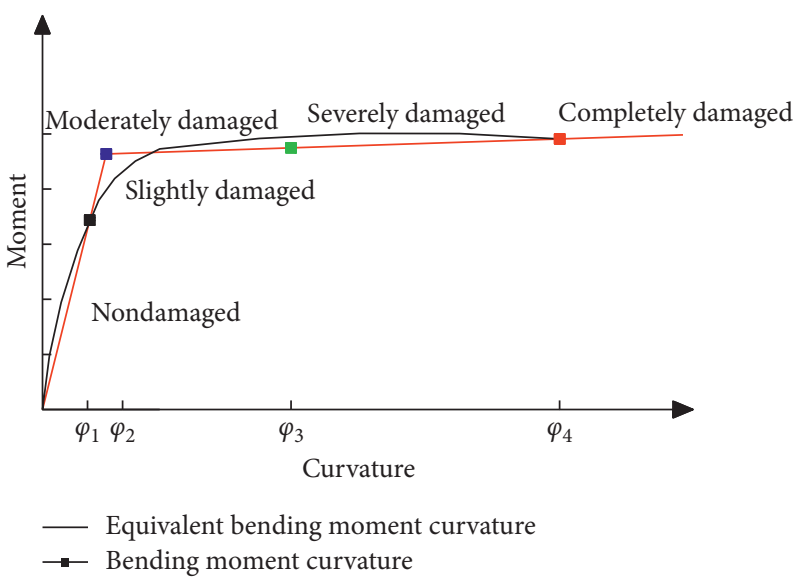

FIGURE 1: Schematic diagram of damage state interval.

TABLE 1: Characteristics of curvature ductility index.

\begin{tabular}{lcc}
\hline Damage degree & Damage characteristics & Specific parameter index \\
\hline $\begin{array}{l}\text { Nondamaged } \\
\text { Slightly damaged }\end{array}$ & $\begin{array}{r}\text { The outermost longitudinal reinforcement is not yielded } \\
\text { compressive strain of unconstrained concrete is less than } 0.004\end{array}$ & $\varphi_{s} \leq \varphi_{y}$ \\
Moderately & $\begin{array}{c}\text { The longitudinal reinforcement strain is less than } 0.55 \text { times of the ultimate tensile } \\
\text { strain, and the constrained concrete is less than } 0.75 \text { times of the ultimate compressive }\end{array}$ & $\varphi_{s h}<\varphi_{s} \leq 0.55 \varphi_{s u}$, \\
damaged & strain & $\varphi_{c o}<\varphi_{c} \leq 0.75 \varphi_{c c}$
\end{tabular}

Note: $\varphi_{s}$ represents the tensile strain of the outermost longitudinal reinforcement of the section; $\varphi_{c}$ represents the compressive strain of unconstrained concrete on the outermost side of the cross section; $\varphi_{y}$ represents the theoretical yield strain of longitudinal reinforcement; $\varphi_{c c}$ represents the compression strain of the outermost constrained concrete of the section; $\varphi_{c o}$ represents the strain corresponding to the peak compressive stress of unconstrained concrete; $\varphi_{s h}$ represents the tensile strain when the longitudinal reinforcement is initially hardened; $\varphi_{c c u}$ represents the tensile strain of the outermost constrained concrete of the section.

that is, curvature index of damage limit state of different pier sections; $\mu_{\text {lns }}$ represents logarithmic mean value of curvature seismic demand.

Analytical fragility functions are useful tools to evaluate the probability of a certain limit state or conditional probability and the basis for resilience [19-21]. There are 3 general ways to develop fragility curves, namely, statistical method, regressive analysis method, and capacity demand ratio method. Based on large number of data entries obtained after analysis by the help of quadratic polynomial fitting process, the capacity demand ratio method tends to be more accurate and precise. Thus, as a result, this method is selected in our study: it uses the scaling approach for intensity measure (IM) and evaluates specific engineering demand parameters (EDP) so that incremental dynamic analysis (IDA) has been performed scaling and applying the selected accelerograms [22]. The fitting curve is expressed as follows:

$$
\begin{aligned}
D I & =A\left[\ln (I M)^{2}\right]+B\left[\ln (I M)^{2}\right]+C, \\
\sigma & =\sqrt{\frac{S_{r}}{(n-2)}}, \\
P_{f} & =P\left[\frac{S_{d}}{S_{c i}}>1\right]=1-\Phi\left[\frac{\ln (1)-\mu}{\sigma}\right]=\Phi\left(\frac{\mu}{\sigma}\right),
\end{aligned}
$$

where $D_{I}$ is seismic demand; $I M$ is intensity measure; $A, B$, and $C$ are the regression parameters; $\sigma$ is standard deviation; $S_{r}$ is residual sum of squares; $n$ is sample number; $P_{f}$ is damage probability; $S_{d}$ is the demand of structural response; $S_{c i}$ is damage index.

2.2. Probabilistic Seismic Hazard Analysis (PSHA). Seismic hazard is defined as the magnitude and frequency of seismic actions that the design site may be subjected to in a 
certain period of time, which is usually expressed by seismic intensity or ground motion intensity. In probabilistic seismic hazard analysis, we analyze the complete design site and find out things like areas prone to future earthquakes and the magnitudes of those earthquakes. Besides, by quantifying the uncertainties and estimating the distribution of earthquake occurrences, PSHA can understand the generation and seismic effects on a region intuitively. At present, it is recognized as the most effective method for seismic hazard analysis.

According to Cornell's point of view, in a reasonable analysis interval, the possibility of seismic hazard can be approximately described by negative power function [13]. It can be expressed by the following equation:

$$
H(x) \approx\left(\frac{x}{u}\right)^{-a} \approx b x^{-a},
$$

where $a$ and $b$ are shape parameters; $u$ is seismic scale parameter; $x$ is ground motion parameter.

In this paper, the ground motion intensity is obtained by fitting the ground motion intensity corresponding to the basic ground motion and the rare ground motion. The site shape parameters $a$ and $b$ can be determined according to the following equation:

$$
\begin{aligned}
a & =\frac{\ln \left(v_{1}(39 \%, 50) / v_{2}(2 \%, 50)\right)}{\ln (\operatorname{Sa}(2 \%, 50) / \operatorname{Sa}(39 \%, 50))} \\
\ln b & =\frac{\ln (\operatorname{Sa}(39 \%, 50)) \cdot \ln \left(v_{2}(2 \%, 50)\right)-\ln (\operatorname{Sa}(2 \%, 50)) \cdot \ln \left(v_{1}(39 \%, 50)\right)}{\ln (\operatorname{Sa}(39 \%, 50) / S a(2 \%, 50))},
\end{aligned}
$$

where $v_{1}$ is basic ground motion; $v_{2}$ is rare ground motion; $x$ is ground motion parameter; $v_{1}(39 \%, 50)$ refers to the annual exceeding probability corresponding to the ground motion, with the intensity of which probably causing the damage probability to $39 \%$ during the 50 -year service period; $\mathrm{Sa}(39 \%, 50)$ means that, in the 50 -year service period, the spectral acceleration corresponds to the ground motion, with the intensity of which probably causing the damage probability to $39 \%$.

\subsection{Probabilistic Seismic Risk Analysis of Bridge. Bridge} probabilistic earthquake risk analysis generally refers to the probability of encountering different earthquake damage during the design basis period, and its expression is as follows:

seismic risk $=$ seismic hazard $\times$ seismic fragility.

From the probabilistic perspective, the probability of a bridge exceeding a certain damage limit state each year can be expressed as follows:

$$
P_{1}=\int_{0}^{+\infty} F_{s}(x) H(x) d x,
$$

where $F_{s}(x)$ is seismic fragility function; $H(x)$ is seismic hazard function; $x$ represents spectral acceleration in this paper.

Incorporate Cornell's substituted seismic fragility function and seismic hazard function into equation (7), and the expression of component probability seismic risk function as shown in equation (8) can be obtained [23]:

$$
\begin{aligned}
P= & H(\phi) \cdot \exp \left(\frac{1}{2} a^{2} \beta^{2}\right)=b\left[\exp \left(\frac{\ln R-k_{0}}{k}\right)\right]^{-a} \\
& \cdot \exp \left(\frac{1}{2} a^{2} \frac{\sigma^{2}}{k^{2}}\right) .
\end{aligned}
$$

To sum up, the main framework of this study is shown in Figure 2.

\section{Case Study}

3.1. General Geometry and Model Details. The Wolonggou Bridge in Gansu Province of China, a long-span continuous rigid frame bridge with high piers, is illustrated as an example in this study. The span of the bridge is $75 \mathrm{~m}+3 \times 140 \mathrm{~m}+75 \mathrm{~m}$ and the width of the bridge is $12.75 \mathrm{~m}$. The overall layout of the bridge is presented in Figure 3(a).

The bridge consists of the main girder made of C55 concrete and the piers made of $\mathrm{C} 40$ concrete. The steel bars used in the main piers are HRB400. The connection between piers and girder is pier-beam consolidation. In the fragility analysis of bridge structures, only the key sections that are prone to damage are generally considered. In Figure 3(b), 16 key sections of the piers are selected according to relevant research results $[24,25]$. The section size of pier 1 is $6.5 \mathrm{~m} \times 7 \mathrm{~m}$, adopted in the form of uniform cross section. The longitudinal and transverse dimensions of pier 2 and pier 3 are sloped to the bottom of the pier. In the range of $30 \mathrm{~m}$ at the pier top, the section is a uniform cross section $(6.5 \mathrm{~m} \times 7 \mathrm{~m})$. In the range of $30-80 \mathrm{~m}$ at the pier top, the two directions are widened at a ratio of $80: 1$ at the same time. In the range of the remaining height, the two directions are widened to the pier bottom at a ratio of $60: 1$. In pier 4 , within the range of $30 \mathrm{~m}$ at the pier top, a uniform cross section of $6.5 \mathrm{~m} \times 7 \mathrm{~m}$ is adopted. The remaining part is widened to the pier bottom longitudinally and transversely at a ratio of $80: 1$. The heights of the four piers are 84 meters, 154 meters, 154 meters, and 110 meters, respectively. The specific geometric position is shown in Table 2 . The main girder adopts a variable cross section form. The schematic diagrams of the mid-span section and the section at the supports are shown in Figures 3(c) and 3(d). 


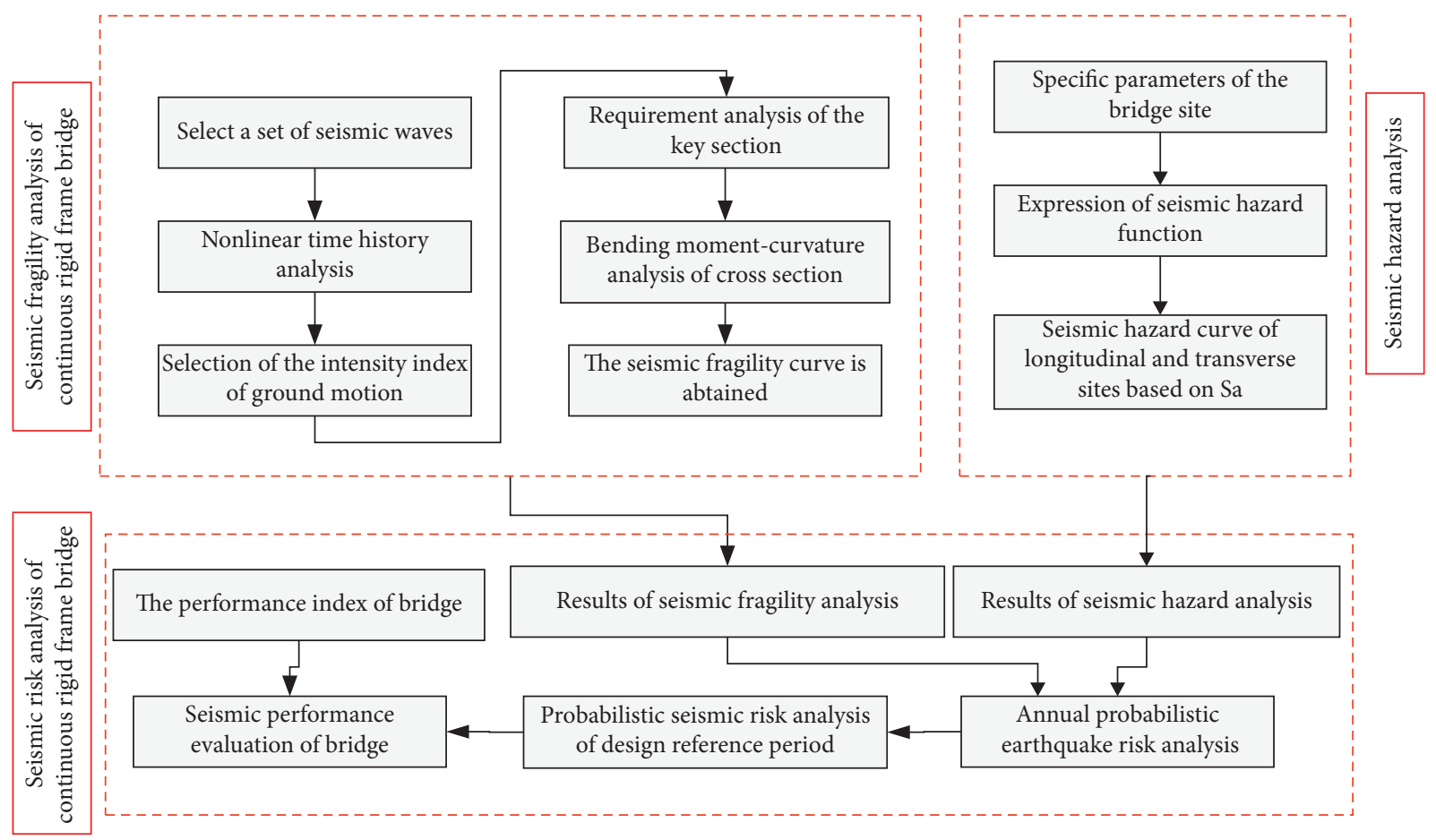

FIGURE 2: The general framework of the analysis implemented in this research.

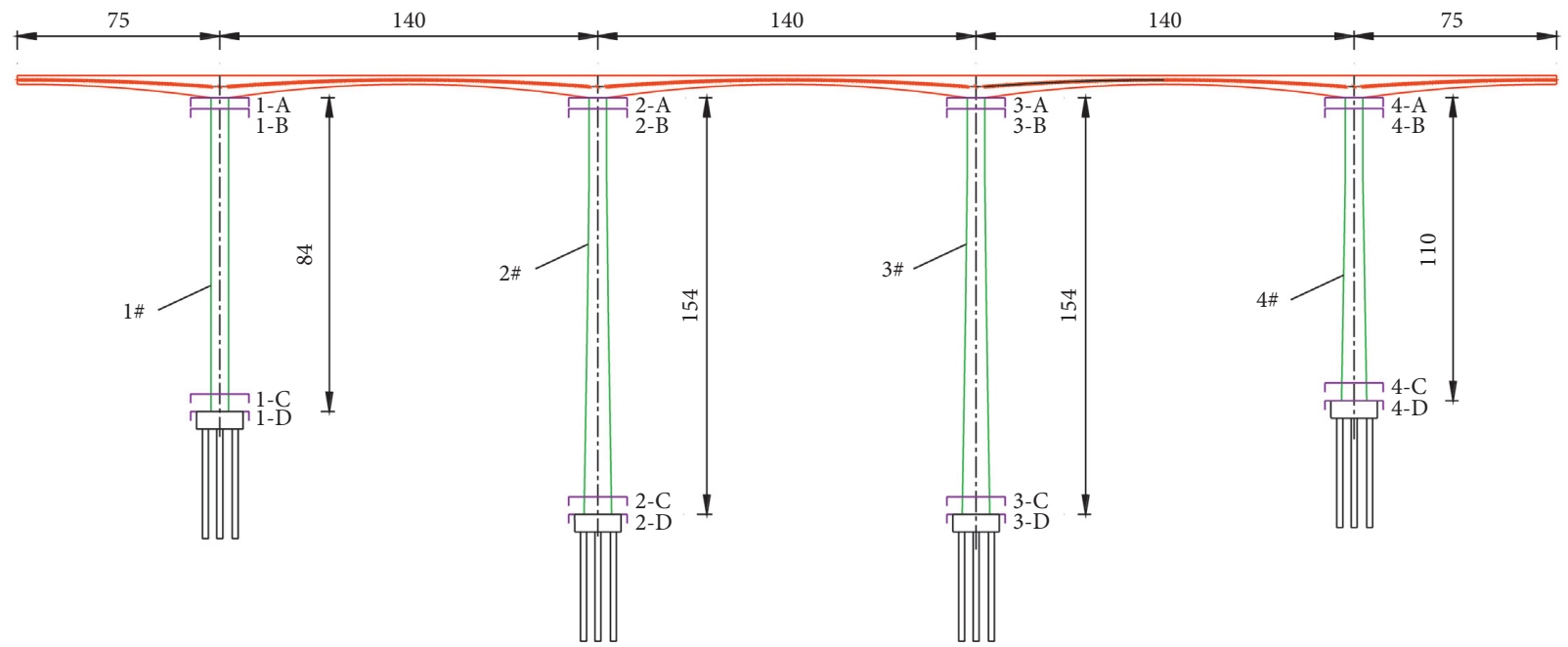

(a)

Figure 3: Continued. 

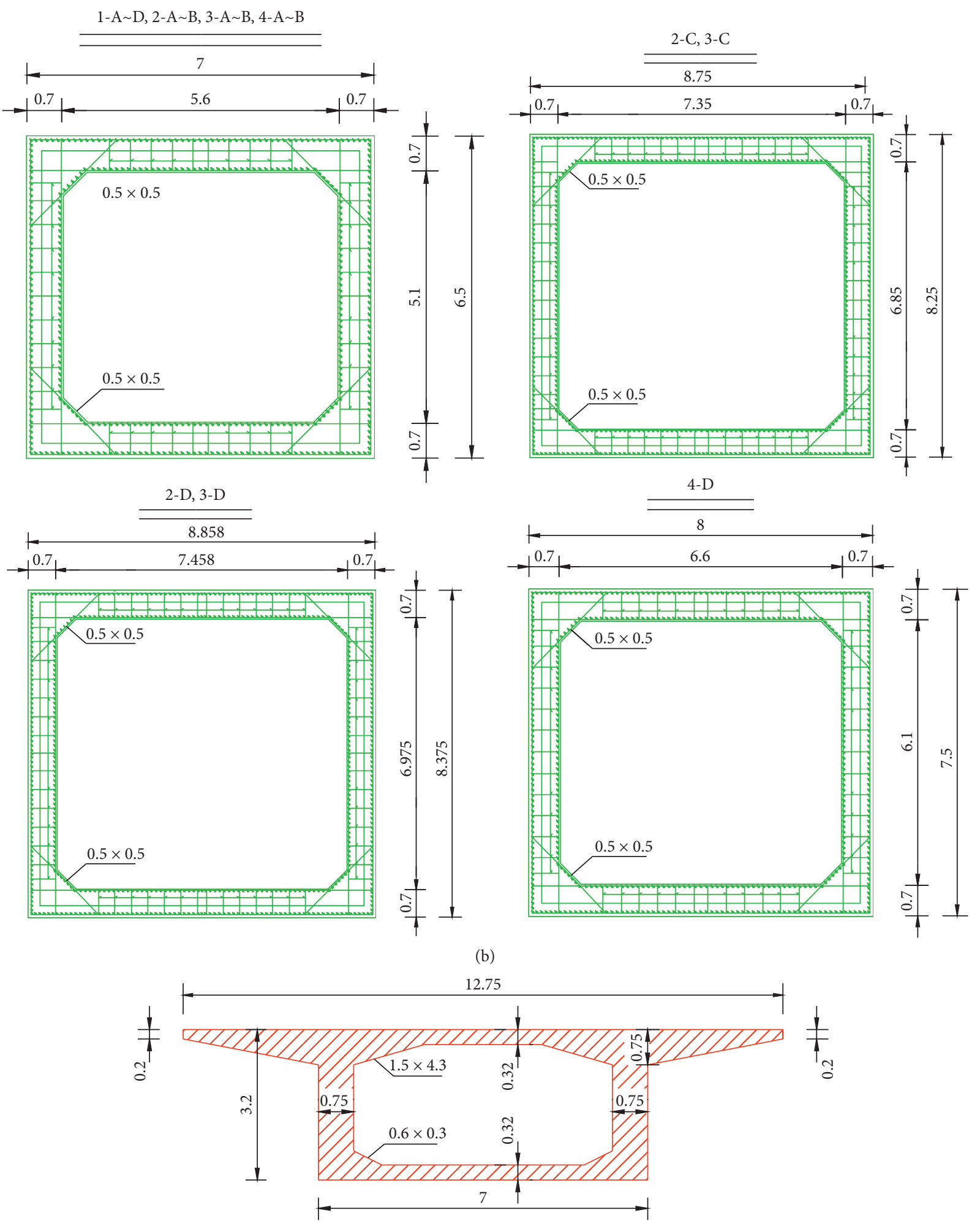

(c)

Figure 3: Continued. 


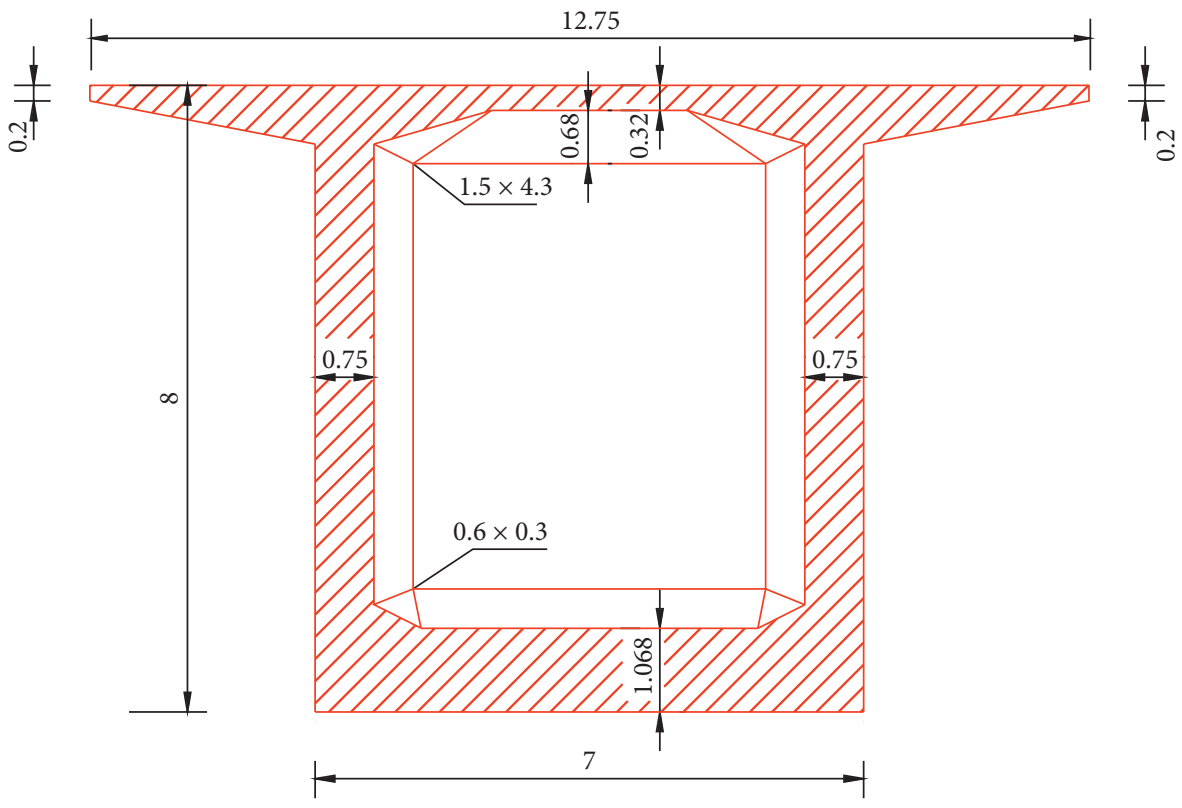

(d)

FIgURE 3: Wolonggou Bridge. (a) A general view of the bridge. (b) The schematic diagram of the midspan section. (c) The schematic diagram of the section at the supports. (d) Key sections of the piers (unit: m).

TABLE 2: The distance between the key section and the bottom of the pier (unit: $\mathrm{m}$ ).

\begin{tabular}{ccccc}
\hline & Section A & Section B & Section C & Section D \\
\hline $1 \#$ & 84 & 80 & 6.5 & 0 \\
$2 \#$ & 154 & 150 & 6.5 & 0 \\
$3 \#$ & 154 & 150 & 6.5 & 0 \\
$4 \#$ & 110 & 106 & 6.5 & 0 \\
\hline
\end{tabular}

The bridge is located in a deep valley with a height difference of $190 \mathrm{~m}$. The peak acceleration of ground motion is $0.1 \mathrm{~g}$ and the characteristic period of the ground motion response spectrum is $0.45 \mathrm{~s}$ in this area.

3.2. Finite Element. In this paper, an FE model (shown in Figure 4) is established by the CSI Bridge software. The constitutive material models of reinforced steel adopt the Giuffre-Menegotto-Pinto hysteretic model, and the constitutive material models of concrete adopt Mander model. The main beam of the bridge is simulated by beam element. For the high pier of the bridge structure, the border of the pier bottom is considered as consolidation, and the pile-soil interaction of the foundation is not considered temporarily. For this reason, the bridge is located in good geological condition, where there is no seismic fault zone. In general, the bridge's main beam is joined to the top surface of different piers of bridge, forming a rigid connection, which in turn would satisfy the demand of real displacement of bridge structure. The end point of the main beam is rigidly connected to the top node of the support. Based on the above considerations, the bridge structure model is established.
As is illustrated in Figure 5, the first-order vibration mode of the bridge structure is drifting in the transverse direction and the basic period is 5.39 s. It can be known that the structure has certain resistance to earthquakes. The third-order vibration mode of the bridge structure is drifting in longitudinal direction, of which the period is $3.21 \mathrm{~s}$.

According to [26], the experimental values are obtained through modal test. In Table 3 , the relative error between experimental and theoretical values of mode vibration is less than $10 \%$. Considering the material simulation, element division, and the difference of actual boundary, it is believed that the FE model is adequate to simulate the dynamic response of the real structure.

\section{Seismic Ground Motion Records}

As mentioned by existing research, the seismic response of the structure will be greatly different due to different seismic records [27]. The selection of suitable ground motion records is a crucial step and should be executed in a way that these ground motion records remain both independent of the type of the structure and applicable to variety of structures at various locations. Also, it is necessary for the number of records to be large enough to cover seismic variability in a more realistic way. According to the previous research, selecting 10 seismic waves can meet the requirements of accuracy when the seismic performance of the structure is evaluated by the incremental dynamic analysis [28]. Consider the particularity of Wolonggou Bridge; 10 seismic waves are selected from the PEER database, for incremental dynamic time-history analysis, and are represented in Figure 6. According to the Chinese standard Guidelines for Seismic Design of Highway Bridges 


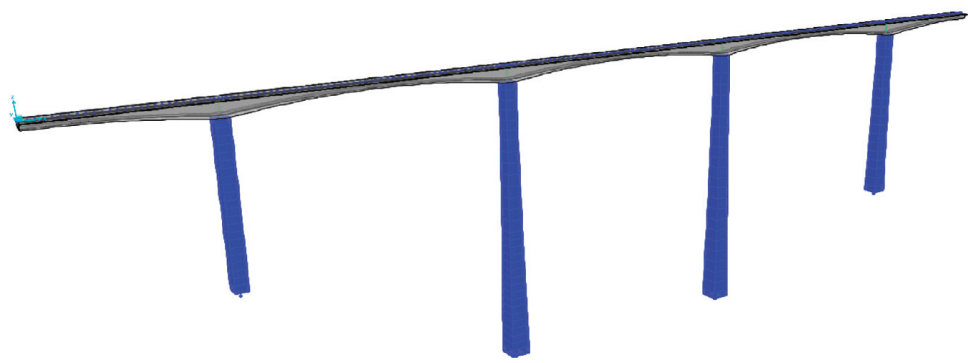

FIGURE 4: Finite element model.

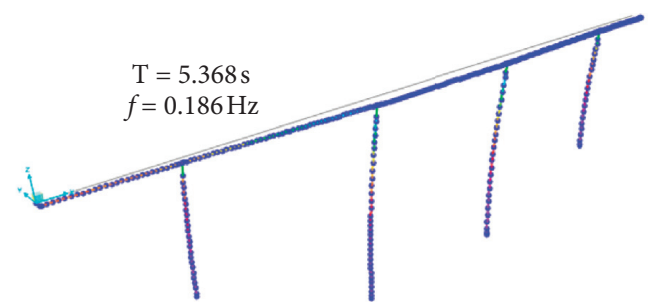

(a)

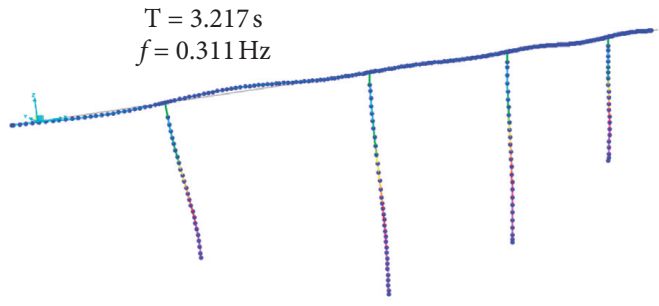

(c)

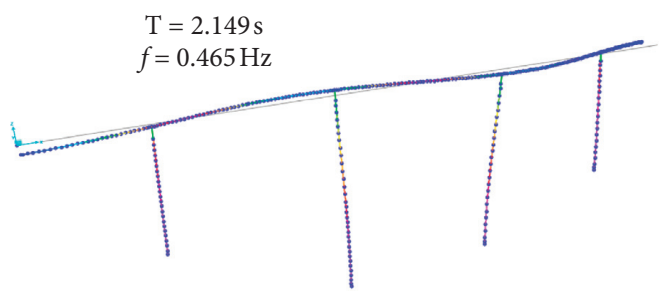

(e)

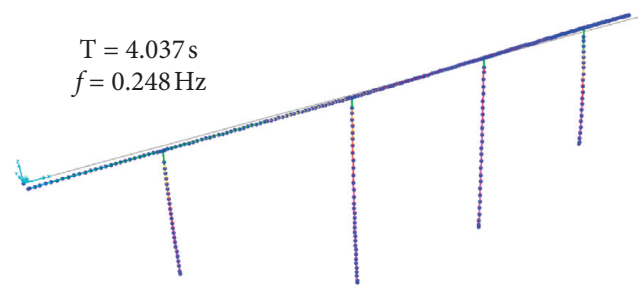

(b)

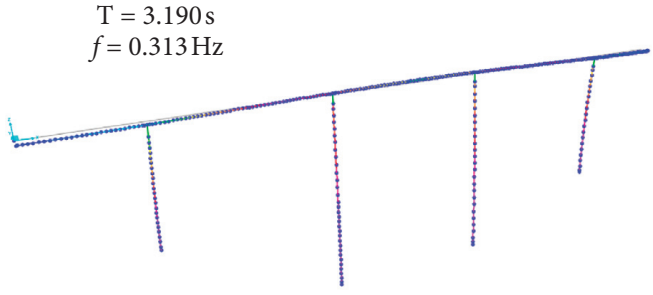

(d)

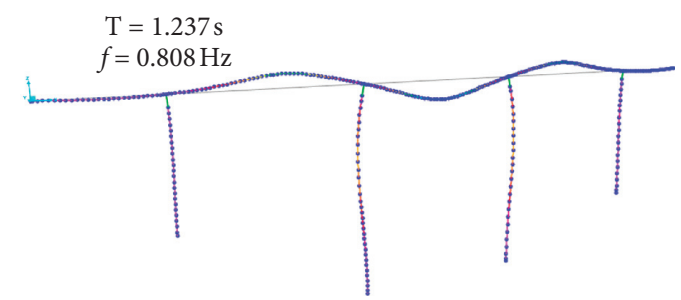

(f)

FIgURE 5: The dimensional model of Wolonggou Bridge in CSI-Bridge. (a) First-order vibration mode. (b) Second-order vibration mode. (c) Third-order vibration mode. (d) Fourth-order vibration mode. (e) Fifth-order vibration mode. (f) Sixth-order vibration mode.

TABLE 3: Multiorder oscillation modal information of Wolonggou Bridge.

\begin{tabular}{lcccc}
\hline \multirow{2}{*}{ Modal order } & \multirow{2}{*}{ Period (s) } & Theoretical values $(\mathrm{Hz})$ & Frequency & Relative value $(\%)$ \\
\hline First order & 5.368 & 0.186 & 0.192 & 3.23 \\
Second order & 4.037 & 0.248 & 0.261 & 5.24 \\
Third order & 3.217 & 0.311 & 0.319 & 2.57 \\
Fourth order & 3.190 & 0.313 & 0.327 & 4.47 \\
Fifth order & 2.149 & 0.465 & 0.493 & 6.02 \\
Sixth order & 1.237 & 0.808 & 0.836 & 3.46 \\
\hline
\end{tabular}




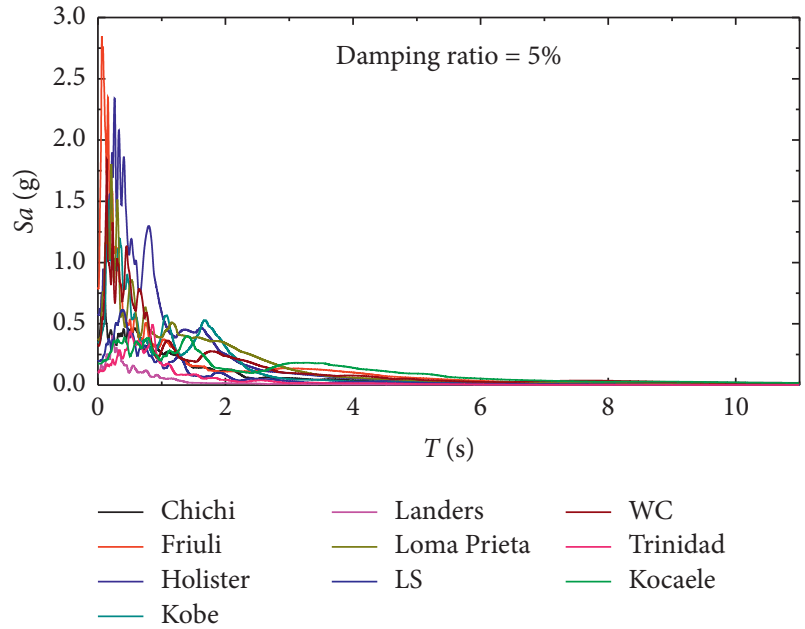

FIgURE 6: The acceleration response spectrum curves of 10 seismic waves.

JTG/T B02-012008 [29], the damping ratio of continuous rigid frame bridge is determined as $5 \%$.

In the selection of appropriate indicators to describe the characteristics of seismic waves, not only can spectral acceleration $\mathrm{Sa}$ take into account the factors (e.g., naturalvibration period and damping ratio) affecting the dynamic characteristics of the bridge structure, but also it can significantly reduce the discreteness in describing the intensity of ground motion. The basic period of Wolonggou Bridge is $3.21 \mathrm{~s}$ in longitudinal directions, so $S a\left(T_{2}=3.21 \mathrm{~s}, \xi=5 \%\right)$ is selected as basic parameter. In the consideration of calculation efficiency, each seismic wave is divided into 10 steps with a step length of $0.05 \mathrm{~g}$ and increased to $0.50 \mathrm{~g}$ step by step. Meanwhile, in transverse directions, $S a\left(T_{1}=5.39 \mathrm{~s}\right.$, $\xi=5 \%)$ is selected as basic parameter. Each seismic wave is divided into 10 steps with a step length of $0.025 \mathrm{~g}$ and increased to $0.25 \mathrm{~g}$ step by step. The specific situation of seismic wave adjustments is shown in Table 4 .

\section{Results and Discussion}

5.1. Seismic Fragility Analysis. The randomness of seismic waves is an important factor that affects the results of fragility analysis. In order to fully understand the seismic response of continuous rigid frame bridge exposed to different seismic excitation, this article only uses a single factor (the uncertainty of seismic actions) for fragility analysis.

5.1.1. Seismic Demand Analysis. Data points obtained from the IDA analysis, after 2400 calculations, are marked in the coordinate system with $\ln (\mathrm{Sa})$ as the abscissa and $\ln \left(S_{d} / S_{c i}\right)$ as the ordinate. Through regression analysis method, the probabilistic seismic demand model of each key section under the excitation of longitudinal and transverse seismic waves is obtained. Due to the large amount of data, only the regression coefficients of pier 1 under the slightly damaged state are listed in Table 5, and the relative regression curves are shown in Figure 7.
Similarly, the seismic demand model of each key section of the remaining piers can be obtained.

5.1.2. Fragility Curves of Key Sections under the Longitudinal Seismic Action. The response mechanism of continuous rigid frame bridge under the longitudinal seismic action can be obtained through Figure 8 . With the height of the bridge piers decreasing, the exceeding probability is increasing. During the longitudinal seismic action, both the top and bottom points of the piers are under the danger of encountering damage, but the top of pier is comparatively more sensitive than the bottom of the pier, making it way more damage prone.

5.1.3. Fragility Curves of Key Sections under the Transverse Seismic Action. By observing Figure 9, it can be seen that, in case of transverse seismic action, lower parts of piers are more exposed than the upper part of pier, making them more sensitive to damage. Thus in a way this case is totally opposite to that of the longitudinal seismic action. Also, in case of transverse seismic action, smaller piers are more vulnerable to damage as compared to taller piers. This being said, the maximum damage state probability within a pier is not at its bottom but the pier body within a certain range near the bottom of the pier. The damage probability at the bottom of pier is larger than that at the top of pier.

5.2. Probabilistic Seismic Hazard Analysis. According to the Guidelines for Seismic Design of Highway Bridges JTG/T B02-012008, the seismic hazard analysis of the design site is carried out [29]. The maximum acceleration response spectrum of horizontal design at the bridge location is calculated by equation (9), and the relative parameters and results are shown in Table 6 and Table 7.

$$
S_{\max }=2.25 C_{i} C_{s} C_{d} A_{b} .
$$

According to Table 6, the approximate expressions of bridge longitudinal and transverse probabilistic seismic hazard function can be obtained:

$$
H(x)=\left\{\begin{array}{ll}
1.957 E-7 \times x^{-2.6086}, & \text { longitudinal direction } \\
5.060 E-8 \times x^{-2.6087}, & \text { transverse direction }
\end{array}\right. \text {. }
$$

\subsection{Probabilistic Seismic Risk Analysis of Bridge Piers during} Design Base Period. As can be seen in Figure 10, with the increase of curvature, the probability of earthquake risk of each pier decreases, which indicates that the seismic capacity of the structure is strong. Under the longitudinal seismic action, the risk probability of the high pier is larger than that of the low pier. Under the transverse seismic action, the risk probability at the bottom of pier is larger than that at the top of pier.

According to Specification of Seismic Design for Highway Engineering JTGB02-2013 [30], two levels of 
TABLE 4: The adjustment of 10 seismic waves.

\begin{tabular}{|c|c|c|c|c|c|c|c|}
\hline \multirow{2}{*}{ ID no. } & \multirow{2}{*}{ Seismic wave } & \multicolumn{3}{|c|}{ Longitudinal } & \multicolumn{3}{|c|}{ Transverse } \\
\hline & & $\mathrm{Sa}(3.21,5 \%)(\mathrm{g})$ & Amplification factor & $\mathrm{Sa}\left(T_{2}\right)(\mathrm{g})$ & $S a(5.39,5 \%)(\mathrm{g})$ & Amplification factor & $\mathrm{Sa}\left(T_{1}\right)(\mathrm{g})$ \\
\hline 1 & Chichi & 0.0489 & 10.31 & 0.50 & 0.02124 & 11.77 & 0.25 \\
\hline 2 & Friuli & 0.02620 & 19.08 & 0.50 & 0.0086 & 29.07 & 0.25 \\
\hline 3 & Holister & 0.02164 & 23.11 & 0.50 & 0.01446 & 17.29 & 0.25 \\
\hline 4 & Kobe & 0.04205 & 11.89 & 0.50 & 0.02019 & 12.38 & 0.25 \\
\hline 5 & Landers & 0.12213 & 4.09 & 0.50 & 0.04500 & 5.56 & 0.25 \\
\hline 6 & Loma Prieta & 0.09980 & 5.01 & 0.50 & 0.03172 & 7.88 & 0.25 \\
\hline 7 & LS & 0.08630 & 5.79 & 0.50 & 0.00353 & 70.82 & 0.25 \\
\hline 8 & WC & 0.00739 & 67.66 & 0.50 & 0.00783 & 31.93 & 0.25 \\
\hline 9 & Trinidad & 0.00596 & 83.89 & 0.50 & 0.00201 & 124.38 & 0.25 \\
\hline 10 & Kocaele & 0.31240 & 1.60 & 0.50 & 0.13063 & 1.91 & 0.25 \\
\hline
\end{tabular}

TABLe 5: The regression coefficients of pier 1 under longitudinal seismic actions.

\begin{tabular}{lcccc}
\hline Section & A & B & C & \multicolumn{1}{c}{$c$} \\
\hline 1A & 0.05217 & 3.29133 & 8.34877 & 1.61710 \\
1B & 0.28293 & 4.04782 & 8.51406 & 1.66457 \\
1C & 0.01107 & 3.34767 & 8.46382 & 1.75298 \\
1D & -0.03861 & 3.23680 & 8.68493 & 1.71518 \\
\hline
\end{tabular}

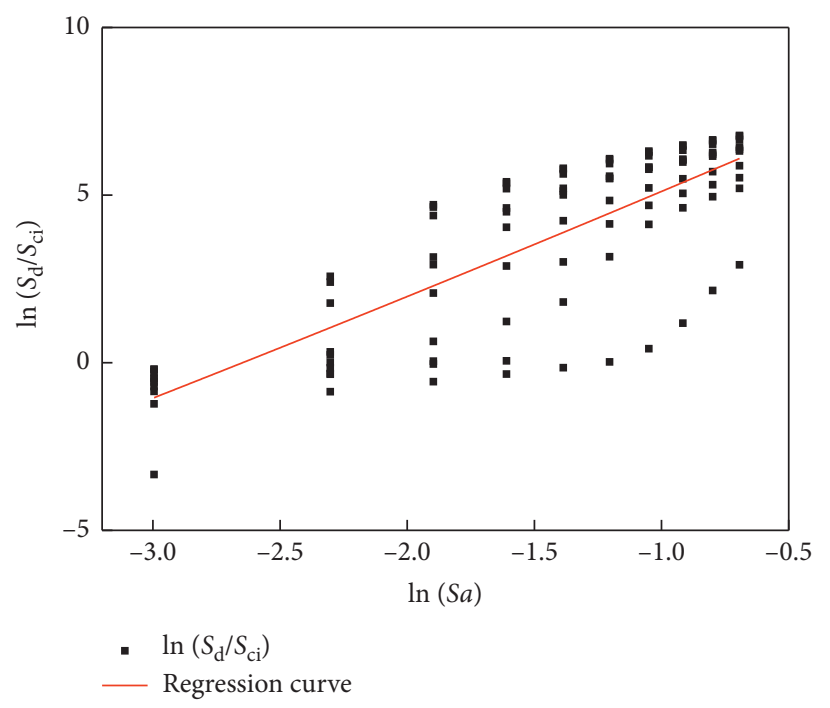

(a)

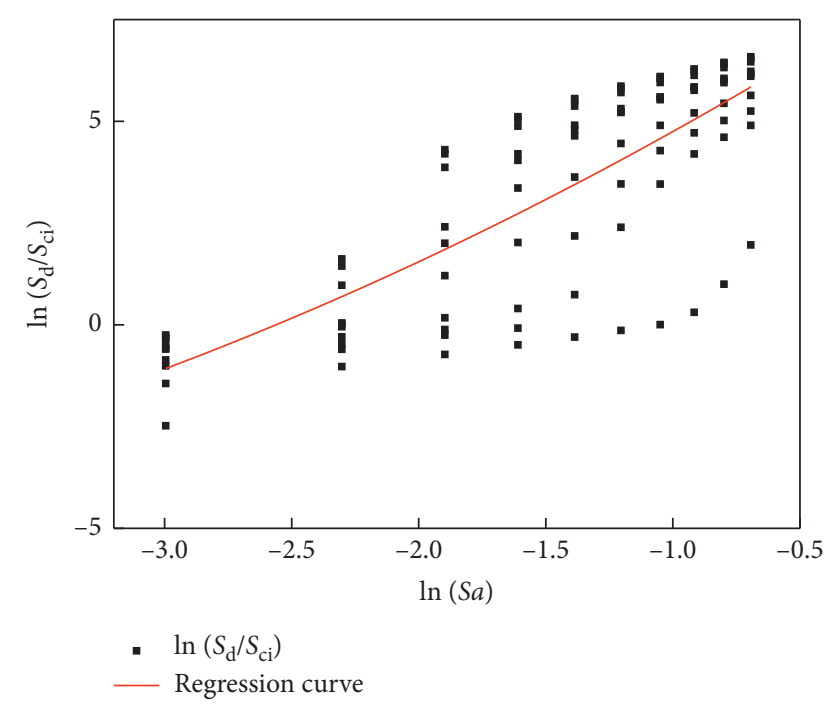

(b)

FIgURE 7: Continued. 


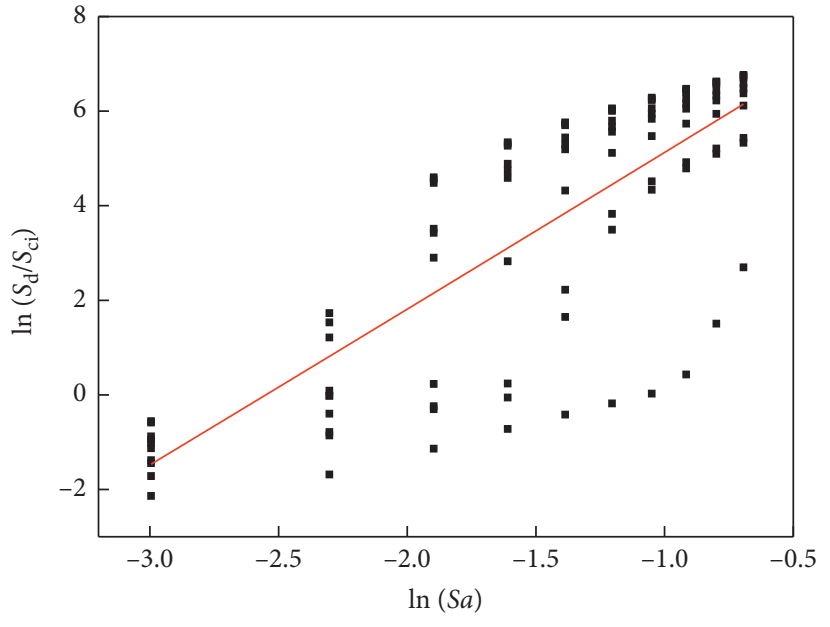

- $\ln \left(S_{\mathrm{d}} / S_{\mathrm{ci}}\right)$

- Regression curve

(c)

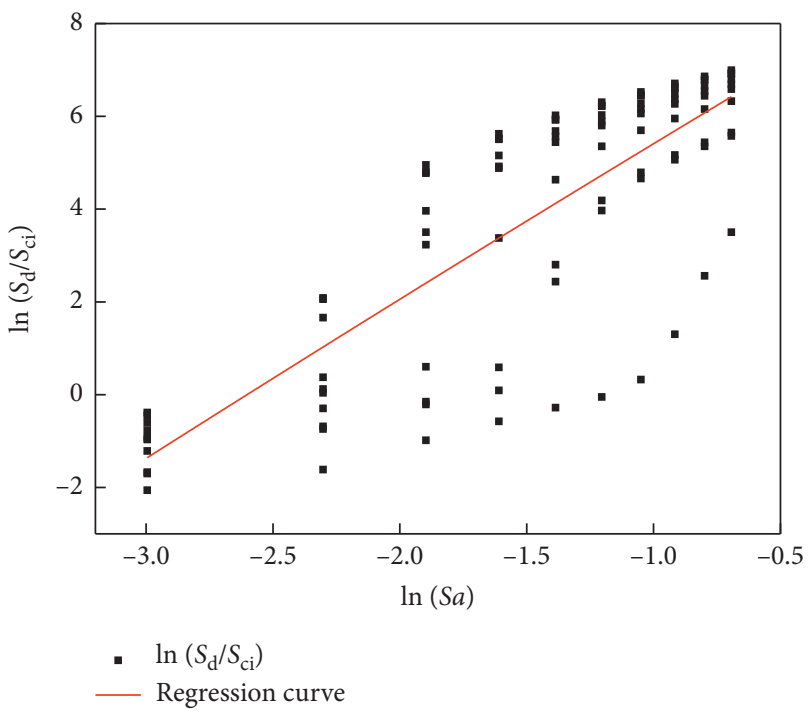

(d)

Figure 7: The regression curves of pier 1 under longitudinal seismic actions. (a) Section 1A. (b) Section 1B. (c) Section 1C. (d) Section 1D.

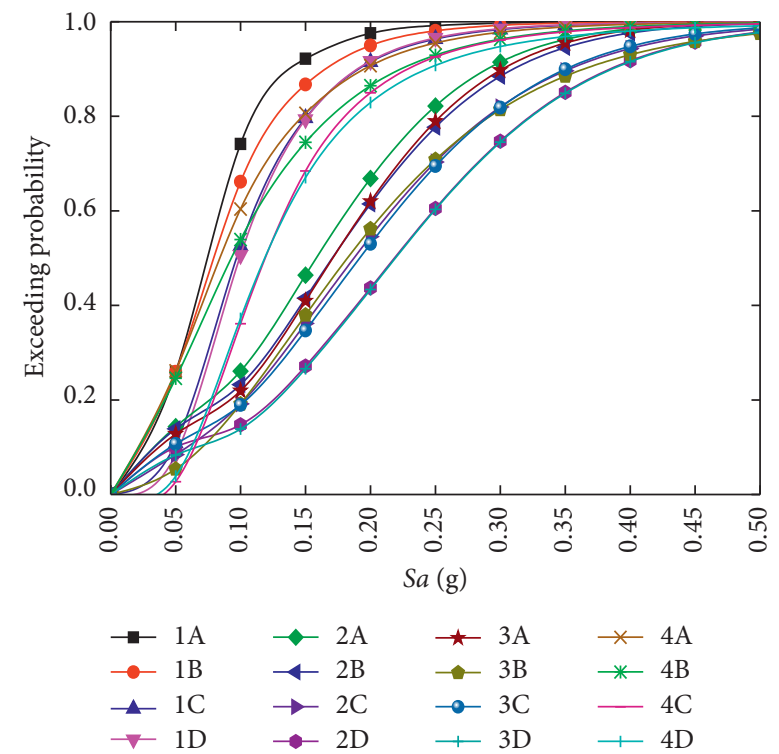

(a)

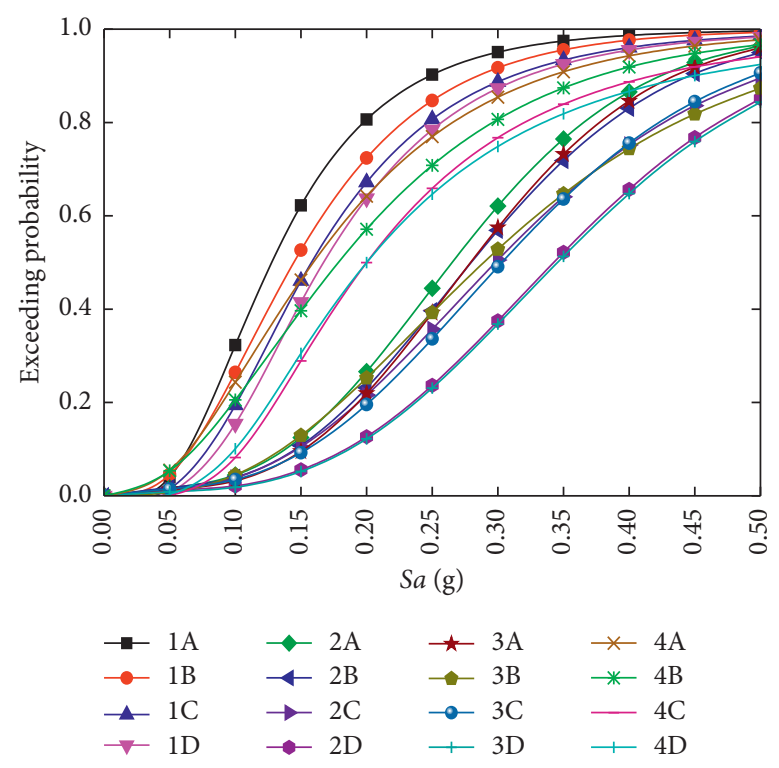

(b)

Figure 8: Continued. 


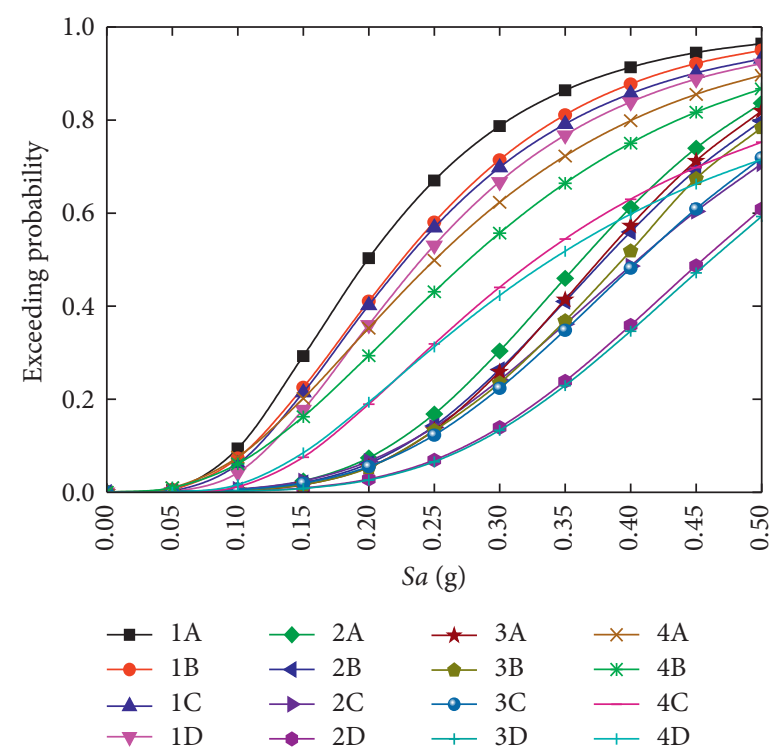

(c)

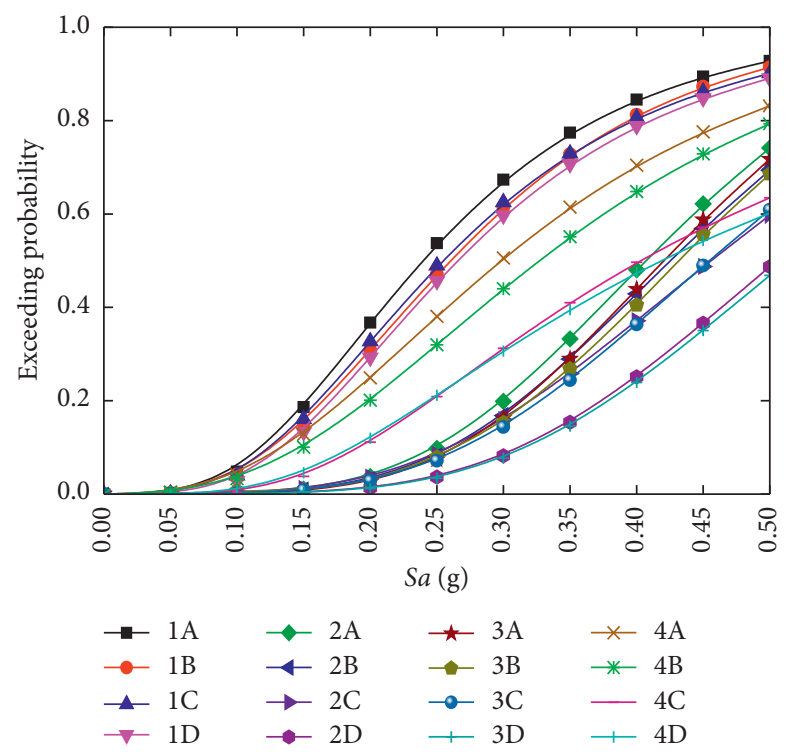

(d)

Figure 8: Fragility curves of key sections under the longitudinal seismic action. (a) Slightly damaged. (b) Moderately damaged. (c) Severely damaged. (d) Completely damaged.
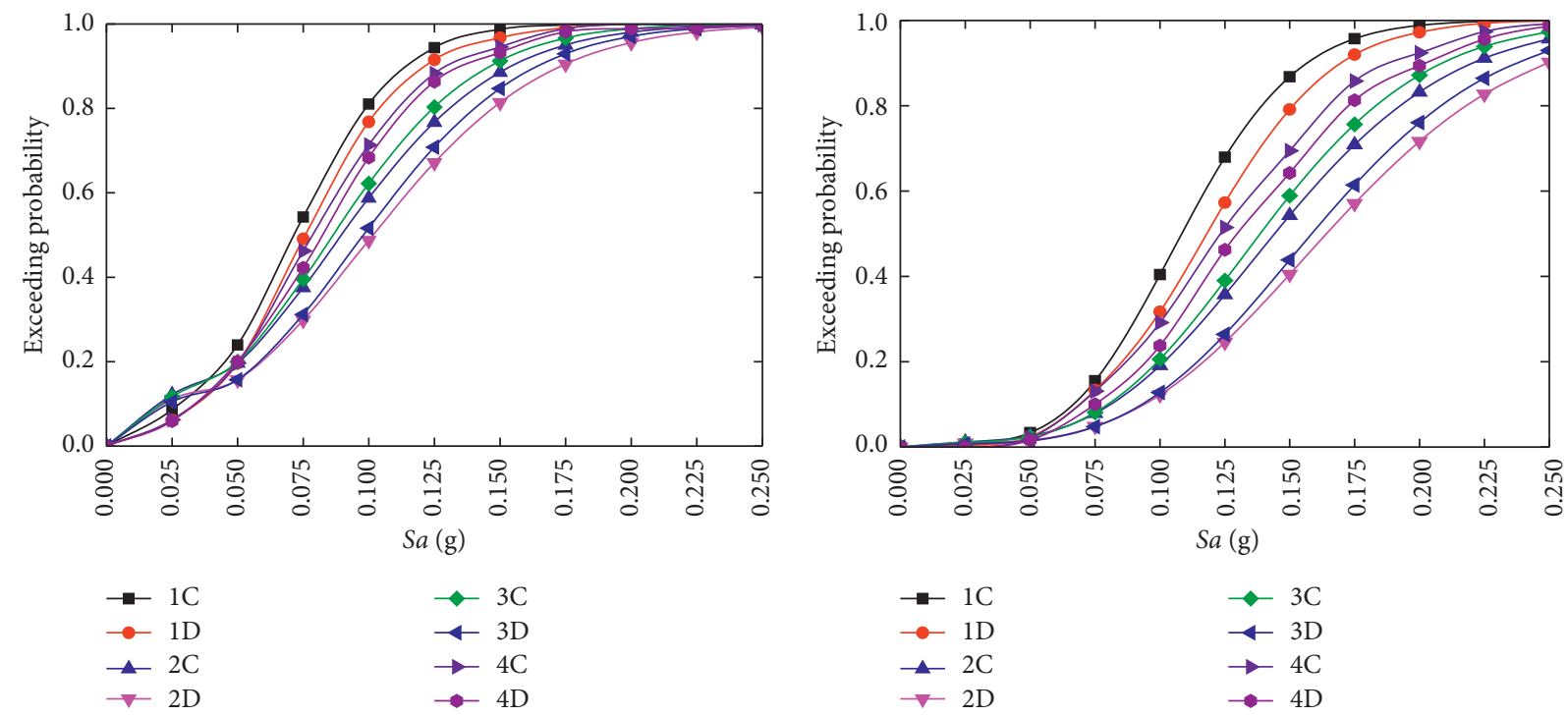

(a)

(b)

FIgURE 9: Continued. 


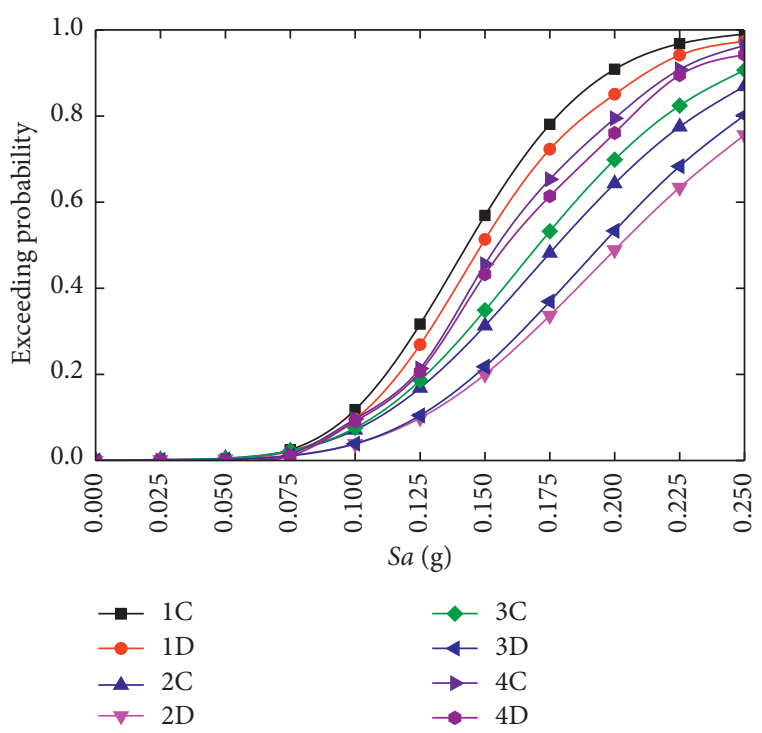

(c)

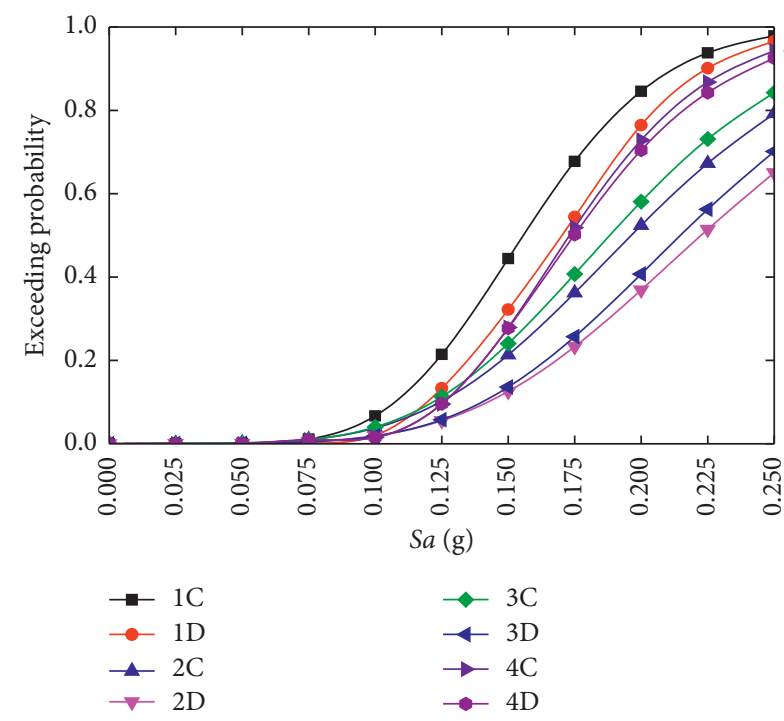

(d)

FIgURe 9: Fragility curves of key sections under the transverse seismic action. (a) Slightly damaged. (b) Moderately damaged. (c) Severely damaged. (d) Completely damaged.

TABLE 6: The relative parameters and results of $S_{\max }$ at the bridge location.

\begin{tabular}{lccccc}
\hline Fortification level & $C_{i}$ & $C_{s}$ & $C_{d}$ & $A_{b}(\mathrm{~g})$ & 0.10 \\
\hline E1 & 1.0 & 1 & 1 & 0.10 & 0.1125 \\
E2 & 1.7 & 1 & 1 & 0.3825 \\
\hline
\end{tabular}

Note: $C_{i}$ represents bridge seismic importance correction factor; $C_{s}$ represents site coefficient; $C_{d}$ represents damping adjustment factor; $A_{b}$ represents basic ground motion peak acceleration horizontal design; $S_{\max }$ represents the maximum acceleration response spectrum of horizontal design.

TABLE 7: Calculated values for the relevant parameters of the seismic hazard function.

\begin{tabular}{lccccc}
\hline Direction & Main mode period $(\mathrm{s})$ & $S a(39 \%, 50)(\mathrm{g})$ & $S a(2 \%, 50)(\mathrm{g})$ & $a$ & $b(\mathrm{E})$ \\
\hline Longitudinal & 3.21 & 0.01577 & 0.05362 & 2.6086 & $1.957 \mathrm{E}-7$ \\
Transverse & 5.39 & 0.00939 & 0.03193 & 2.6087 & $5.060 \mathrm{E}-8$ \\
\hline
\end{tabular}

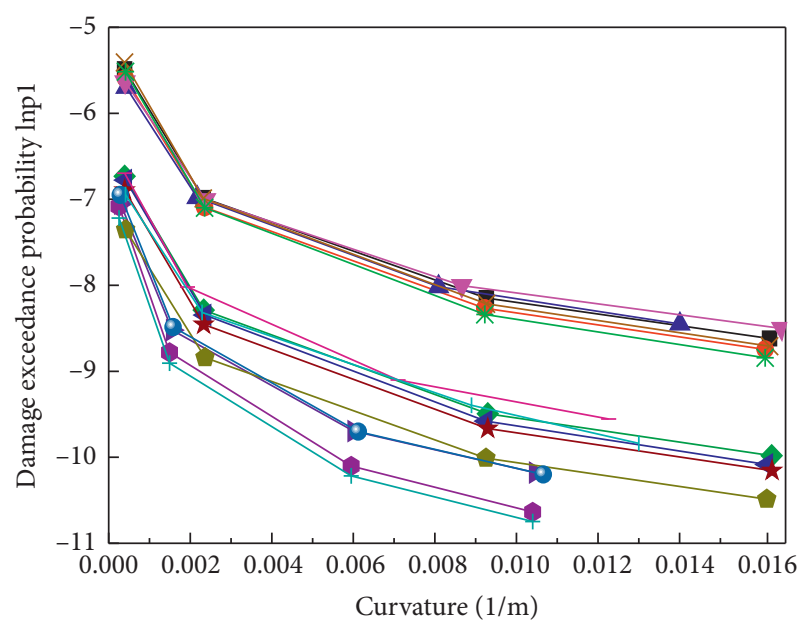

$$
\begin{array}{llll}
\rightarrow-1 \mathrm{~A} & -2 \mathrm{~A} & - \text { 3A } & * 4 \mathrm{~A} \\
-1 \mathrm{~B} & -2 \mathrm{~B} & -3 \mathrm{~B} & * 4 \mathrm{~B} \\
-1 \mathrm{C} & \rightarrow 2 \mathrm{C} & -\mathrm{C} & -4 \mathrm{C} \\
-1 \mathrm{D} & -2 \mathrm{D} & +3 \mathrm{D} & -4 \mathrm{D}
\end{array}
$$

(a)

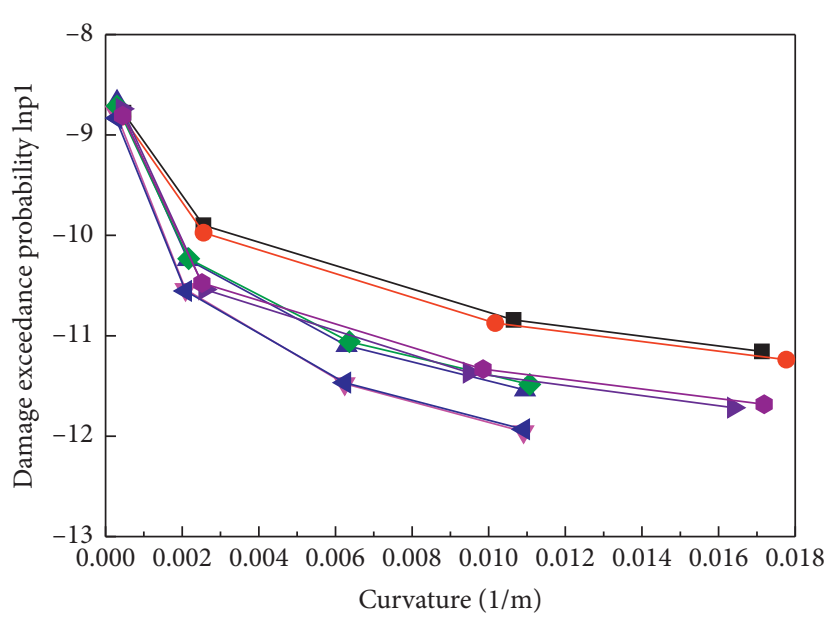

Curvature $(1 / \mathrm{m})$

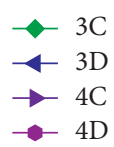

(b)

FIgURE 10: Probability curve of seismic damage risk in design reference period. (a) Longitudinal. (b) Transverse. 
TABLE 8: Longitudinal and transverse risk probability of key sections of piers during the design reference period.

\begin{tabular}{lcccc}
\hline Direction & Slightly damaged (\%) & Moderately damaged (\%) & Severely damaged (\%) & Completely damaged (\%) \\
\hline Longitudinal & 33.92 & 8.89 & 3.29 & 2.12 \\
Transverse & 1.71 & 0.50 & 0.20 & 0.14 \\
\hline
\end{tabular}

fortification are chosen in the process of considering seismic fortification. On the basis of the statistical theory, the relationship between the exceeding probability within the 100year design reference period and the exceeding probability within one year is as follows:

$$
P_{T}=1-\left(1-P_{1}\right)^{T}
$$

where $P_{1}$ is annual seismic risk probability of the bridge structure; $P_{T}$ is the seismic risk probability of the bridge structure within the 100-year design reference period.

Based on the probability curves of seismic damage risk of each pier under longitudinal and transverse seismic actions, the longitudinal and transverse risk probabilities of the key sections of the pier during the design reference period are obtained.

According to Table 8 , the risk probability of slight damage in longitudinal and transverse directions is less than $63 \%$, which can meet the E1 seismic fortification standards. The risk probability of moderate damage under longitudinal seismic action is $8.89 \%$, which cannot meet the E2 seismic fortification standards. Meanwhile, under transverse seismic action, it can meet the E2 seismic fortification standards, whose risk probability of moderate damage is $0.50 \%$. Therefore, the seismic damage of bridge structure cannot completely meet the fortification standard of the current seismic code of highway bridge, but the maintainability and noncollapse of components can be guaranteed.

\section{Conclusions}

Using CSI bridge (a nonlinear software) and capacity demand ratio method, the effects that different earthquake directions had on the probabilistic response of continues rigid frame bridge were observed and studied. The damage exceeding probability curves of the key sections of four piers under the longitudinal and transverse seismic actions is obtained, and approximate expression of longitudinal and transverse probabilistic seismic hazard function of the structure is derived. On the basis of both, the seismic risk of continuous rigid frame bridges with high piers under the longitudinal and transverse seismic actions is further analyzed. The main conclusions can be outlined as follows:

(1) When an earthquake occurs, the top and bottom ends of the piers of any long-span continuous rigid frame bridge are the ones that first undergo plastic deformation. When we consider the longitudinal seismic action, top portion of the pier is most prone to damage, whereas when talking about the transverse seismic action, the bottom end of the pier is most vulnerable to damage. The damage probability of low pier is larger than that of high pier. At this point, the direction of the ground motion has little effect on it.

(2) Regardless of longitudinal or transverse seismic actions, the probability of severe and complete damage to each key sections of the piers is less than $5 \%$ during the design reference period, which indicates that the bridge will not collapse or cause casualties by an earthquake. When considering the seismic uncertainty only, the risk probability of longspan continuous rigid frame bridge in longitudinal directions is much bigger compared with the transverse directions.

(3) In the seismic design of long-span continuous rigid frame bridge, under the longitudinal seismic action, the seismic performance of the pier top should be given utmost importance. Meanwhile, under the transverse seismic action, attention should be paid to the seismic response of the pier bottom. Besides, the height difference between low piers and high piers on the seismic fragility of bridges should be considered synthetically.

In this paper, the earthquake loss analysis of high-pier long-span continuous rigid frame bridge has not been studied due to the lack of relevant data on the loss of personnel and property. The further detailed research is still needed according to the estimation of relevant earthquake loss at the bridge site.

\section{Data Availability}

The data used to support the findings of this study are available from the corresponding author upon request.

\section{Conflicts of Interest}

The authors declare that there are no conflicts of interest regarding the publication of this paper.

\section{Acknowledgments}

This research was funded by projects of the National Natural Science Foundation of China (51408040), Natural Science Foundation of Shaanxi Provincial Department of Education (2017JM5110), Science and Technology Plan Project of Shaanxi Provincial Department of Communications (17$15 \mathrm{~K})$, and Natural Science Research of Anhui University (KJ2019A1134). 


\section{References}

[1] Z. J. Sheng and L. Z. Hong, "The status quo and developing trends of large-span prestressed concrete bridges with continuous rigid frame structure," China Journal of Highway and Transport, vol. 13, no. 1, pp. 31-37, 2000, in Chinese.

[2] L. G. Li, "Numerical analysis of seismic resistance of high pier large span concrete continuous rigid frame bridge," Highway Engineering, vol. 43, no. 5, pp. 248-251, 2018, in Chinese.

[3] D. S. Shan, E. H. Zhang, J. Dong et al., "Ground motion attenuation characteristics of Wenchuan earthquake and seismic response law of long-span continuous rigid frame bridge with high-rise pier," China Civil Engineering Journal, vol. 50, no. 4, pp. 107-115, 2017, in Chinese.

[4] C. W. Jiang, W. J. Yi, and Y. T. Pang, "Correlation between seismic intensity indices and damages of large span rigid frame bridges," China Journal of Highway and Transport, vol. 29, no. 9, pp. 97-102, 2016, in Chinese.

[5] L. Li, S. Hu, and L. Wang, "Seismic fragility assessment of a multi-span cable-stayed bridge with tall piers," Bulletin of Earthquake Engineering, vol. 15, no. 9, pp. 3727-3745, 2017.

[6] Z. W. Chen, Q. H. Pu, X. Li, and H. Jia, "Fragility analysis of large-span continuous rigid bridge considering wave passage effect," Journal of Southwest Jiaotong University, vol. 52, no. 1, pp. 23-29+37, 2017, in Chinese.

[7] J. G. Zhao, H. Y. Jia, X. Li et al., "Fragility analysis of high-pier and long-span continuous rigid frame bridge based on double effects of the actual site and collision," Journal of South China University of Technology (Natural Science Edition), vol. 47, no. 1, pp. 64-74, 2019, in Chinese.

[8] H. Jiang, J. M. Jin, Z. G. Wang, X.-Y. Bai, and M. Wang, "Probabilistic seismic damage characteristics for piers of deep-water continuous rigid frame bridge based on IDA method," China Journal of Highway and Transport, vol. 30, no. 12 , pp. 89-100, 2017, in Chinese.

[9] R. Akbari, "Seismic fragility analysis of reinforced concrete continuous span bridges with irregular configuration," Structure and Infrastructure Engineering, vol. 8, no. 9, pp. 873-889, 2012.

[10] Y. Liang, J. L. Yan, Z. Q. Cheng et al., "Time-varying seismic fragility analysis of offshore bridges with continuous rigidframe girder under main aftershock sequences," Journal of Bridge Engineering, vol. 25, no. 8, 2020.

[11] Y. T. Pang, J. G. Wang, Y. H. Ou et al., "Seismic fragility analysis of a continuous rigid frame bridge made from steel fiber reinforced concrete," Journal of Harbin Engineering University, vol. 39, no. 4, pp. 687-694, 2018, in Chinese.

[12] H. Feng and F. W. Wu, "Seismic fragility analysis of cablestayed bridge considering the degradation of the bearing material," Journal of Changchun Normal University, vol. 38, no. 8, pp. 1-7, 2019, in Chinese.

[13] J. T. Li, Q. S. Yang, and Y. B. Liu, "Fragility analysis of long span continuous rigid frame bridge under multi-support excitations," Journal of Vibration and Shock, vol. 32, no. 5, pp. 75-80, 2013.

[14] C. Qin, L. Q. Xu, J. C. Liu et al., "Comparative study on long period seismic response of long span continuous rigid frame bridges with high piers," Journal of China \& Foreign Highway, vol. 37, no. 1, pp. 72-78, 2017, in Chinese.

[15] J. Dong, D. S. Shan, E. H. Zhang et al., "Seismic fragility of irregular continuous rigid frame bridge," Journal of Southwest Jiaotong University, vol. 50, no. 5, pp. 845-851+878, 2015, in Chinese.
[16] Y. J. Park and A. H. S. Ang, "Mechanistic seismic damage model for reinforced concrete," Journal of Structural Engineering, vol. 111, no. 4, pp. 722-739, 1985.

[17] W. P. Wu, L. F. Li, L. H. Wang et al., "Evaluation of seismic vulnerability of high-pier long-span bridge using incremental dynamic analysis," Earthquake Engineering and Engineering Dynamics, vol. 32, no. 3, pp. 117-123, 2012.

[18] F. W. Wu, J. F. Luo, W. Zheng et al., "Performance-based seismic fragility and residual seismic resistance study of a long-span suspension bridge," Advances in Civil Engineering, vol. 2020, Article ID 8822955, 2020.

[19] Q. Wang, Z. Y. Wu, and S. K. Liu, "Multivariate probabilistic seismic demand model for the bridge multidimensional fragility analysis," KSCE Journal of Civil Engineering, vol. 22, no. 9, pp. 3443-3451, 2018.

[20] Z. Zheng, X. L. Pan, and X. Bao, "Seismic fragility of a typical containment under bidirectional earthquake excitations," KSCE Journal of Civil Engineering, vol. 22, no. 11, pp. 44304444, 2018.

[21] W. P. S. Dias and U. Edirisooriya, "Derivation of tsunami damage curves from fragility functions," Natural Hazards, vol. 96, no. 3, pp. 1153-1166, 2019.

[22] M. Bayat, F. Daneshjoo, and N. Nisticò, "The effect of different intensity measures and earthquake directions on the seismic assessment of skewed highway bridges," Earthquake Engineering and Engineering Vibration, vol. 16, no. 1, pp. 165-179, 2017.

[23] C. A. Cornell, "Engineering seismic risk analysis," Bulletin of the Seismological Society of America, vol. 58, no. 5, pp. 1583-1606, 1968.

[24] Z. T. Huang, Probabilistic Seismic Fragility and Risk Analysis of Long Span Continuous Rigid Frame Bridge with High Steel Tube-Reinforced Concrete Column, Southwest Jiaotong University, Chengdu, China, 2015, in Chinese.

[25] A. J. Ye and Z. G. Guan, Seismic Design of Bridge, China Communications Press, Beijing, China, 2011, in Chinese.

[26] Y. Y. Meng, Performance-based Seismic Fragility and Risk Analysis of High Pier and Long Span Continuous Rigid Frame Bridge, Chang'an University, Xi'an, China, 2019, in Chinese.

[27] Y. Y. Wang, X. D. Liu, and M. X. Cheng, "Study on the input of earthquake ground motion for time-history analysis of structures," Journal of Building Structures, vol. 12, no. 2, pp. 5l-60, 1991.

[28] M. P. Wang, X. J. Cao, and W. L. Sun, "Incremental dynamic analysis applied to seismic risk assessment of hybrid structure," Earthquake Resistant Engineering and Retrofitting, vol. 32, no. 1, pp. 109-121, 2010.

[29] Ministry of Transport of the People's Republic of China, JTG/ T B02-01 2008: Guidelines for Seismic Design of Highway Bridges, China Communications Press, Beijing, China, 2008, in Chinese.

[30] Ministry of Transport of the People's Republic of China, JTGB02-2013: Specification of Seismic Design for Highway Engineering, China Communications Press, Beijing, China, 2014, in Chinese. 